\begin{tabular}{cc}
$\begin{array}{c}\text { Yanbu Journal } \\
\text { of } \\
\text { Engineering } \\
\text { and Science }\end{array}$ & \\
\hline \hline ISSN: $1658-5321$ & $\begin{array}{c}\text { Vol. 2, April 2011 }(1432 \mathrm{H}) \\
\text { www.yic.edu.sa/yjes }\end{array}$
\end{tabular}

\title{
MEAN VALUE ANALYSIS WITH COMBINATIONAL ROUTING AND YIELD PROBABILITIES FOR A POWER SOAK RE-ENTRANT OPERATION
}

\author{
Suresh Kumar \\ Electronics and Instrumentation Engineering Technology, Yanbu Industrial College, Saudi Arabia. \\ Email:skumar@yic.edu.sa
}

\begin{abstract}
Queueing networks arising from multistage processes with probabilistic re-entrant lines are common in manufacturing environments. Probabilistic re-entrant flow is defined as lots entering the operation with different repeated cycle requirements. This paper presents a computational model based on the mean value analysis (MVA) technique considering a probabilistic re-entrant operation with yield probabilities for a Power Soak operation. The objective of this work is to develop a solution method to determine the total cycle time and the mean throughput for a Power Soak operation in a semiconductor back end industry. In addition, a method based on the saturation of the mean throughput, is developed to determine the maximum number of lots and the target cycle time for the operation. Using analytical and simulation methods, comparison results are made under various probabilistic re-entrant and yield conditions. Results show that the analytical model developed has close agreement with the simulation results. The method proposed can be used by operations managers to determine their lots' cycle times and the maximum number of lots and eventually tie to the performance of the operation.
\end{abstract}

KeYWords: Probabilistic re-entrant, Mean value analysis, Lot clustering, Total cycle time, Mean throughput

\section{INTRODUCTION}

This paper considers a queuing problem arising from a Power Soak operation in a semiconductor back-end manufacturing industry. This operation is a five-stage process with probabilistic re-entrant lines. Lots entering the operation have different repeated cycle requirements and this makes the re-entrant probabilistic in nature. It is unlike deterministic re-entrant flow where lots will have fixed cycle needs. This re-entrant process is subjected to certain probabilities, which are governed by the external demand. Products or lots are re-entered into the previous stages and they continue to be processed for second and subsequent cycles. The Power Soak operation is designed for the power integrated circuits modules, stressed with high voltage and current. This research focuses on the development of a queueing model based on the mean value analysis (MVA) technique to determine the total cycle time to complete a given number of lots and subsequently calculate the mean throughput of the Power Soak operation. The yield at each stage is taken into consideration in the computations. The total cycle time (makespan) is defined as the time taken to complete the entire process sequence for a given number of 
lots. The mean throughput is the average number of lots that can be completed in a time period. The intention of this research is to answer several critical questions such as:

- What is the total cycle time and throughput needed to complete the entire Power Soak operation for a given number of lots?

- What is the maximum number of lots that can be loaded into the operation for a given combinational routing probability with yield consideration?

- What is the target cycle time (cycle time goal) that can be established as a baseline for the combinational routing probabilities with yield consideration?

The operations manager will be able to determine the approximate time needed to complete a certain number of lots of different cycle requirements. In addition, they will also be able to monitor the performance of the operation. This paper is organized as follow; section 2 provides some previous related work, section 3 deals with the research environment, section 4 explain the model formulation with section 5 summarizes the algorithm and section 6 provides the computational experiences and discusses the results. Section 7 concludes this work.

\section{PREVIOUS WORK}

Gross and Harris [1] and Park et al. [7] in their work defined mean value analysis (MVA) based on two fundamental principles:

1. The queue length observed by an arriving customer or job is the same as the overall distribution in a closed network system seen by an outsider with one less customer or job in the system.

2. Little's Law [5] is applied to relate the mean queue length with the arrival rate and the mean waiting time.
Gross and Harris [1] presented a single server $\mathrm{M} / \mathrm{M} / 1$ fundamental equation for analyzing closed queueing networks by means of the mean value analysis (MVA) technique. The implication of the equation is that the duration an arriving customer or job must wait is the average time to serve the queue size as seen by an arriving customer or job plus its own service time. The MVA is an iterative method for analyzing queueing systems under steady state conditions. Thus, the method is used as the fundamental methodology for this research. Gross and Harris [1] have included a routing probability matrix into their MVA algorithm which is based on a traffic equation. Traffic equation is useful in analyzing probabilistic routing conditions. Gross and Harris [1] have compared the results obtained from the MVA method and normalizing constant method and found that both produce the same results. Normalizing constant method requires steady state probabilities to compute the queueing length but the MVA algorithm can directly calculate the queue length and waiting time without deriving the steady state probabilities. This simplifies the computational process and is useful to develop extension models to represent other types of queueing networks.

Narahari and Khan [6] in their work considered re-entrant manufacturing systems with inspection stations placed at various stages. Their creative idea was to find alternative locations to place inspection stations at various stages of processing. The performance measures were cycle time and throughput. Inspection stations were intended to ensure and track quality and process performance and at the end of the inspection, there were three possible outcomes: accept, reject or rework. Thus, the system has a reentrant line that is probabilistic in nature with yield consideration. They formulated an 
approximate analytical technique method based on MVA to compute mean steady state cycle times and throughput rates. The method clearly models scheduling policies used in reentrant lines for rapid performance analysis. Thus, the method is able to determine the minimum number of inspection stations and the optimal location to maximize throughput. The shortcoming of their method is that the reject rates have to be small. Their method might not be able to handle large reject rates coming from the inspection station, as it would create instability in the system.

Park et al. [8] proposed an approximate approach for analyzing the performance of a re-entrant line with single or batch machines and multi-class jobs using the MVA technique. The main difference was that multi class jobs were considered as compared to the earlier work. In addition, the re-entrant lines also consist of both single job machines and batch machines. Multiclass jobs were assumed to be flowing through predetermined routes and the routes may be different for different classes of jobs. In most of the re-entrant lines studies done previously, the cycle time computed were linearly proportional to the number of jobs in the system and did not require adjustments to the model. However in Park et. al's [7] paper, some heuristic corrections were made to their mean cycle time for workstations that contained batch machines. They have also taken an additional step by evaluating the model with a large number of jobs going beyond one hundred. A cutoff point was determined to indicate at what number of lots the correction should be implemented. Their work was conducted under ideal condition and nothing was mentioned about the variation of the arrival of jobs into the system.

Park et al. [8] extended their previous work by considering random production losses due to machine failures and yields. Losses were considered in their MVA model, as they believed that it represents the real system. In their previous work, the performance measures of interest were the steady state average of the cycle time of each job class, queue length of each buffer and the throughput of the system. The methodology used is an iterative procedure based upon MVA with some heuristic adjustments.

Kumar and Omar [2] developed an algorithm for a five stage two-cycle probabilistic re-entrant line using the MVA technique for an environmental screening cycling (EST) operation. The algorithm developed was based on MVA and traffic equation proposed by Gross and Harris [1]. Their intention was to compute the mean waiting time and mean throughput rate. In their work, they found that as the number of lots in the system increase beyond 40 , the errors exceed 5\%. Thus, a correction factor was introduced into the model to adjust the mean waiting time for more that 40 lots in the system. However, the correction factor formulation developed is limited to their five stage network only. Any extension of the stage would require a revamp in correction factor formulation.

Kumar [3, 4] developed a solution method to determine the total cycle time of a Reflow Screening (RS) operation in a semiconductor assembly plant. It has multiple re-entrant the flow. The uniqueness of this operation in [4], is that it has to be borrowed from another department in order to perform production screening task.

In this research work, we propose an extended analytical method based on MVA and lot clustering technique $[11,12]$ to be used in the probabilistic re-entrant line for the Power Soak operation. It is a method developed to allow the operations managers to measure the 
cycle time in terms of lot clusters. The objectives are to determine the total cycle time and mean throughput of the Power Soak operation with process yield consideration.

\section{RESEARCH ENVIRONMENT}

Modeling of a queueing network with probabilistic re-entrant lines is the main research theme, which specifically focuses on a Power Soak operation in the semiconductor back-end manufacturing industry. Power Soak operation is where the semiconductor power products or commonly known as integrated circuits (ICs) are subjected to severe voltage and current to weed out products that are electrically weak. Lots that undergo this operation are electrically tested before proceeding to the subsequent cycle. If there is a high rate of defective units in a particular lot then the entire lot is rejected and removed from the system.

The workflow block as shown in Fig.1. depicts a five-stage Power Soak operation with each stage having an operator responsible to execute the job. Lots from the main production are sent for the Power Soak process. Each lot that enters into this operation will have its own number of cycles.

For instance, lot 1 requires 2 cycles, lot 2 requires 3 cycles, lot 3 requires 1 cycle and so on until $\mathrm{N}$ lots and they are predetermined externally. In stage 1, the lots are identified and are provided with lot documentation.

Lots will come into the operation and reside in a buffer called buffer $b_{11}$ before lot documents are generated for each lot. Lots will then move to the second stage into buffer $\mathrm{b}_{21}$ and wait for their turn to be processed. In this stage the individual units of a lot are inserted into the sockets of the printed circuit board designed for the products. Each type of product will have its own dedicated boards.

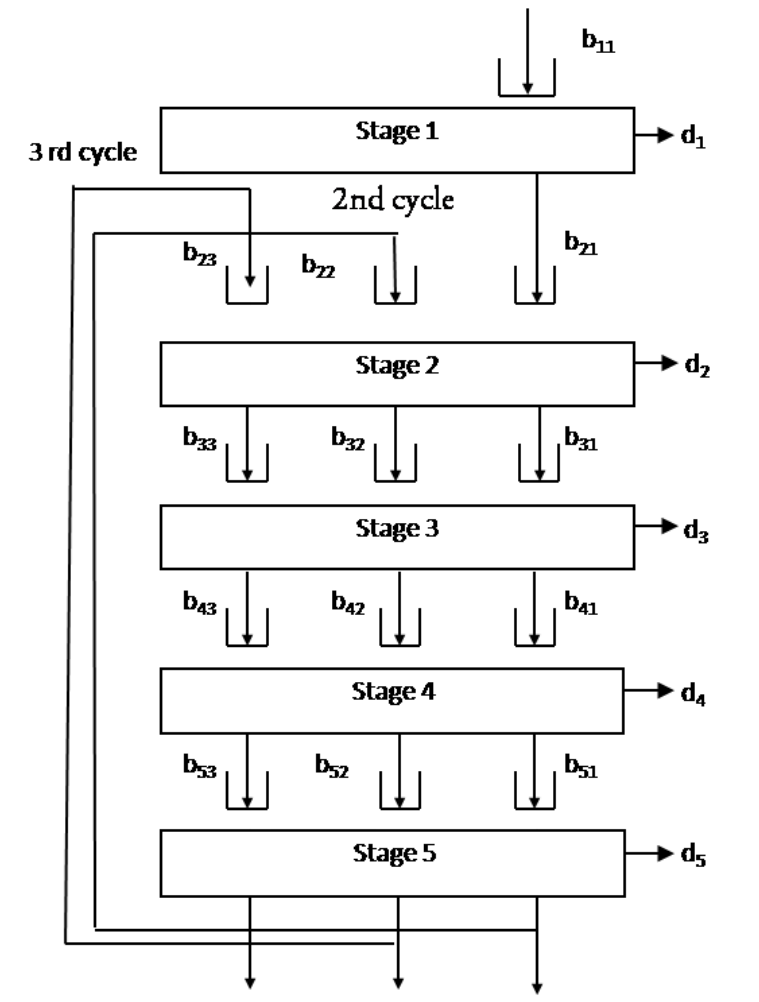

Fig.1. Block diagram of the Power Soak operation by stages

Upon completing this process, the lots will then move to buffer $b_{31}$ at stage 3 and are subsequently the boards having the units are connected to the power supply and electricity is turned for a fixed duration. Upon completion of the electrical stress, the boards are removed from power supply and put in buffer $b_{41}$ to be cooled. Units are later unloaded from the boards and tubed or packed. The lots will move to stage 5 into buffer $b_{51}$ and wait for electrical testing in order to verify if the products are in good condition. Any unit from a lot that is found to be defective is rejected and is removed from the lot for failure analysis. The quantity of the lot will be reduced and if the reduction is significant, the processing time of the lot will also change. It is assumed that a small number of defected units do not change the processing time of the lot in the subsequent cycles. However, if the number of defective units is 
beyond a set value, then the entire lot is rejected and will be removed from the system. Lots that are removed from a particular stage are considered as yield losses for that stage. Either the good lots will be re-entered to stage 2 into buffer $b_{22}$ for the next cycle or the lots will leave the operation after stage 5 . The lots that are re-routed will move into buffers $\mathrm{b}_{22}, \mathrm{~b}_{32}, \mathrm{~b}_{42}$ and $\mathrm{b}_{52}$ and processed accordingly. Thus, not all of the lots will go through the same number of cycles and this creates a probabilistic nature of the re-entrant line.

\section{MODEL FORMULATION}

The Power Soak operation has five stages with $l$ th cycle buffers at every stage. When the lots come into any stage from the previous one, the lots will queue in their respective cycle buffer before they are processed. Buffers are temporary waiting place before the lots undergo the process stage. In this case the lots will be processed on a first come first serve basis. At every stage, one operator is assigned to perform the stage specific task defining a single server system. The stages are serially connected in a queueing network. After the last stage, lots are fed back into the second stage and will undergo repeated cycles as required by the lots. The re-entrant process is governed by a pre-determined probability based on the cycle demand. The assumption made is that the operation is not affected by any disturbances, interruptions or additional setup time.

\subsection{MVA EQUATIONS}

MVA equations are based on the arrival theorem and Little's law [5]. Arrival theorem defined by Reiser and Lavenberg [9] states that the queue length observed by an arriving customer to a workstation is the same as the overall queue length seen by an outside customer when system's customer population is less by one. Little's law gives a relationship between mean queue length with the arrival rate and mean waiting time. Thus the mean waiting time of lots in buffer $b_{i}$ is

$\mathrm{W}_{\mathrm{i} l}(\mathrm{k})=\frac{\mathrm{L}_{\mathrm{i} l}(\mathrm{k}-1)}{\mu_{\mathrm{i} l}}+\frac{1}{\mu_{\mathrm{i} l}}$

The total cycle time for $\mathrm{k}$ number of lots in the operation having $\mathrm{P}$ number of re-entrant lines is derived as

$\mathrm{W}_{\mathrm{T}}(\mathrm{k})=\sum_{\mathrm{i}=1}^{\mathrm{M}} \sum_{l=1}^{\mathrm{P}} \mathrm{W}_{\mathrm{i} l}(\mathrm{k})$

Equation (2) indicates that all $\mathrm{k}$ lots will go through all the buffers in its route. Applying Little's Law for the population of lots in the system, the throughput is obtained as

$\lambda(\mathrm{k})=\frac{\mathrm{k}}{\mathrm{W}_{\mathrm{T}}(\mathrm{k})}$

The mean queue length at every buffer is

$\mathrm{L}_{\mathrm{i} l}(\mathrm{k})=\lambda(\mathrm{k}) \mathrm{W}_{\mathrm{i} l}(\mathrm{k})$

The initial conditions for the iterations are

$\mathrm{L}_{\mathrm{i}}(0)=0, \mathrm{~W}_{\mathrm{il}}(0)=0, \lambda(0)=0$

The total cycle time has to be adjusted based on the probabilities of re-entrant flows. The total cycle time is computed by an iterative method with the given initial conditions. The algorithm shown above indicates that all $\mathrm{k}$ number lots will pass through every buffer before exiting out from the system. However, in this study the nature of the re-entrant flow is not purely deterministic but depends on the number of cycles the lots are required to go through. For instance if $\mathrm{k}$ number of lots require $l$ cycles and the balance $\mathrm{N}-\mathrm{k}$ number lots the lot requires $l+1$ cycles, thus a probabilistic re-entrant flow situation occurs.

\subsection{LOT CLUSTERING APPROACH}

In deterministic routes, $\mathrm{k}$ number of lots is consistent over the entire routes. On the other hand, in our operation each lot that enters into the operation has different cycle requirements. The $\mathrm{k}$ lots do not go through 
the same defined routes. It would be tedious to compute the cycle time of an individual lot entering the operation due to the different requirements of each lot. In order to solve this problem, lot clustering approach is taken whereby lots are virtually gathered in groups. There is no physical batching of the lots. In the lost clustering approach, lots will enter into the operation buffer $b_{11}$ as usual in a serial manner. A cluster of $\mathrm{N}$ lots is identified as they enter and the percentage number of lots for each cycle is noted. For example, for a cluster of 10 lots, $60 \%$ require two cycles and $40 \%$ require only one cycle. This brings about the probabilistic routing, $r_{l}$ on the re-entrant lines. Thus, modification is made to the total cycle time of $\mathrm{N}$ number of lots that is circulating the system. The advantage of this method is that, batching of the lots is not required at the entrance. Hence, no additional waiting time and cost is required to physically batch or group the lots. In addition, this method reduces the computation complexity compared to using the traffic equation method. The total cycle time can be computed in terms of the number of lots circulating in the system.

\subsection{COMBINATIONAL ROUTING PROBABILITIES}

Since the first Power Soak stage has only one buffer, $b_{11}$ and all $\mathrm{N}$ number of lots requires going through this stage, adjustment of stage 1 cycle time is not required at this stage. The re-routing affects the other stages since the lots require to re-enter from stage 2 onwards. The $\mathrm{P}$ value is set to the highest number of cycles in an identified cluster of lots. The waiting time from stage 2 to 5 is

$\mathrm{W}(\mathrm{N})=\mathrm{W}_{\mathrm{T}}(\mathrm{N})-\mathrm{W}_{11}(\mathrm{~N})$

Every lot that enters into the operation has to undergo at least one cycle. The other subsequent cycles until $\mathrm{P}$ will have its own routing probability. This is explained in the following numerical example. If 10 lots are clustered with $60 \%$ of the lots requires two cycles and $40 \%$ require one cycle, the waiting time $\mathrm{W}(10)$ can be proportionally divide. $\mathrm{W}(10)$ is the total cycle time for 10 lots with two cycles of Power Soak. W(10)/2 is the cycle time for 10 lots with one cycle of stress test. Thus the waiting time for 6 lots is $0.6^{*} \mathrm{~W}(10)$ and waiting time for 4 lots is $0.4^{*} \mathrm{~W}(10)$. The sum of both the times will be the total cycle time. The total re-entrant probability will always be one. The total cycle time of $\mathrm{N}$ lots is adjusted by a combinational routing probability, $\mathrm{r}_{\mathrm{T}}$ which can be determined by equation (7)

$\mathbf{r}_{T}=\frac{\sum_{l=1}^{\mathrm{P}} l \mathbf{r}_{l}}{\mathbf{P}}$

\subsection{Combinational ROUTING With CUMULATIVE YIELD PROBABILITIES}

Sometimes when an operator processes the lots at each stage, rejecting certain defective lots is possible. If this happens then the defected lots will be removed from the particular stage. The number of lots circulating in the operation will be affected and hence the combinational routing probabilities have to be modified. An arriving lot will go through all the stage and will encounter with a defect probability $\mathrm{d}_{\mathrm{i}}$. Thus the cumulative yield probability, $\mathrm{D}_{\mathrm{T}}$, is given by equation (8).

$\mathrm{D}_{\mathrm{T}}=\left(1-\mathrm{d}_{1}\right) \times\left(1-\mathrm{d}_{2}\right) \times\left(1-\mathrm{d}_{3}\right) \times\left(1-\mathrm{d}_{4}\right) \times\left(1-\mathrm{d}_{5}\right)$

The cumulative yield probabilities affect the number of lots for any routing probabilities when lots repeatedly go through the stages. During the re-entrants, cumulative yield probabilities have to be considered repeatedly. Thus, combinational routing with cumulative yield probabilities is given by equation (9).

$\operatorname{Dr}_{T}=\frac{\sum_{l=1}^{\mathrm{P}} l \mathrm{r}_{l}\left(\mathrm{D}_{\mathrm{T}}\right)^{l}}{\mathrm{P}}$ 
Thus the total cycle time when applying the combinational routing with yield probabilities is given by equation (10).

$\mathrm{DW}_{\mathrm{T}}(\mathrm{N})=\operatorname{Dr}_{\mathrm{T}} \cdot \mathrm{W}(\mathrm{N})+\mathrm{W}_{11}(\mathrm{~N})$

The mean throughput is computed using equation (11).

Mean throughput $=\frac{\mathrm{N}}{\mathrm{DW}_{\mathrm{T}}(\mathrm{N})}$

4.5 DETERMINATION OF MAXIMUM NUMBER OF LOTS AND TARGET CYCLE TIME

As far as the above calculation method is concerned, the cycle time will continuously increase as the number of lots in the operation increases. However, in the actual operation the number of lots will not increase to a very large number. From throughput point of view, as the number of lots increases after a certain number the throughput will not increase but remains constant. This is because the operation has reached its bottleneck capacity. The throughput begins to saturate at the point when the number of lots in the operation reaches its maximum point. The reason for this point to be considered maximum is because any increase in the number of lots will not affect any change in the throughput and this indicates that the operation is at its maximum capacity for a given routing probability.

This maximum number of lots $\left(\mathrm{N}_{\max }\right)$ is a very important information to the laboratory manager as he/she is able to determine the number of lots the operation can accommodate comfortably and is able to set the total cycle time target, which is defined as $\mathrm{T}_{\text {goal. }}$.

$\mathrm{T}_{\text {goal }}=\mathrm{DW}_{\mathrm{T}}\left(\mathrm{N}_{\max }\right)$

Any desired increase in the number of lots beyond $\mathrm{N}_{\max }$ the manager knows that help would be needed in the operation to reduce the cycle time below $\mathrm{T}_{\text {goal. }} \mathrm{T}_{\text {goal }}$ is determined from the cycle time values corresponding to the $\mathrm{N}_{\max }$ under normal operating conditions. Both these values become a baseline or reference for the Power Soak operation.

\section{SUMMARY OF THE ALGORITHM}

The overall steps are to compute the total cycle time and mean throughput rate are summarized below. Various routing probabilities can be applied to this algorithm.

Step 1: Initialize all variables

$$
\mathrm{L}_{\mathrm{i} /}(0)=0, \quad \mathrm{~W}_{\mathrm{i} l}(0)=0, \lambda(0)=0, \mathrm{M}=5, \mathrm{k}=0
$$

Step 2: Determine $\mathrm{r}_{l}, \mathrm{~d}_{\mathrm{i}}, \mathrm{N}$ and $\mathrm{P}$ required value

Step 3: Increase $\mathrm{k}$ by 1

Step 4: Compute $\mathrm{W}_{\mathrm{i}}(\mathrm{k})$ and $\mathrm{W}_{\mathrm{T}}(\mathrm{k})$ using equation 1 and 2

Step 5: Compute $\lambda(\mathrm{k})$ and $\mathrm{L}_{\mathrm{il}}(\mathrm{k})$ using equations (3) and (4)

Step 6: If $\mathrm{k}=\mathrm{N}$, then go to step 7 or else go to step 3

Step 7: Compute $\mathrm{W}(\mathrm{N}), \mathrm{r}_{\mathrm{T}}, \mathrm{D}_{\mathrm{T}}, \mathrm{Dr}_{\mathrm{T}}, \mathrm{DW}_{\mathrm{T}}(\mathrm{N})$ and mean throughput using equations (7), (8), (9) and (10).

Step 8: Determine $\mathrm{N}_{\max }$ from the mean throughput rate curve or the earliest point where the mean throughput begins to be constant.

Step 9: Obtain the $\mathrm{DW}_{\mathrm{T}}{ }^{*}\left(\mathrm{~N}_{\text {max }}\right)$ and equate to $\mathrm{T}_{\text {goal. }}$.

\section{COMPUTATIONAL EXPERIENCE AND RESULTS}

In order to validate the proposed model, several tests were performed. In our validation tests, the cycle time obtained by the proposed MVA method was compared with simulation results. The routing probabilities are determined upon clustering of the lots when they arrive into the system. In this research, simulation model was developed using software package "Taylor ED 2000" by Taylor [10]. Extensive simulation runs were made in order to obtain steady state results. The obtained analytical values and simulated 
values are used to calculate the relative absolute errors as shown in equation (13).

$\%$ difference $=\left|\frac{\text { MVA Value }- \text { Simulation Value }}{\text { Simulation Value }}\right| \times 100 \%$

Consider a cluster of incoming $\mathrm{N}$ number of lots requiring a maximum of $\mathrm{P}$ cycles of screening cycles. If $r_{1}=0.3, r_{2}=0.5$ and $r_{3}=0.2$, it means that $30 \%$ of the $\mathrm{N}$ number of lots require only 1 cycle of screening, $50 \%$ require 2 cycles of screening and $20 \%$ require 3 cycles of screening. The mean processing time for jobs at each buffer by the respective operators:

$$
\begin{aligned}
& \frac{1}{\mu_{11}}=15 \text { minutes } \\
& \frac{1}{\mu_{21}}=\frac{1}{\mu_{22}}=\frac{1}{\mu_{21}}=15 \text { minutes } \\
& \frac{1}{\mu_{31}}=\frac{1}{\mu_{32}}=\frac{1}{\mu_{31}}=10 \text { minutes } \\
& \frac{1_{41}}{\mu_{41}}=\frac{1_{42}}{\mu_{41}}=20 \text { minutes } \\
& \frac{1_{51}}{\mu_{51}}=\frac{1_{52}}{\mu_{5 l}}=30 \text { minutes }
\end{aligned}
$$

Several combinations of routing and yield probabilities are tested and compared with the simulation results. Table 1 shows the various combinational routing and yield probabilities tested in the model. In practice, most of the time the lots would require 3 cycles and below. Thus for the validation process, $\mathrm{P}$ value is taken as 3 cycles. For every number of lots, 1000 simulated runs with a simulation speed of $200 \mathrm{hr} / \mathrm{sec}$ stretched over 100 days were performed and the average cycle time was computed. These were enough to achieve the desired level of accuracy for this operation. The 95\% confidence interval is computed automatically by the software for the selected arrival distribution and the service distribution. The cycle time estimate is calculated with the assumption of normality. The output mean cycle time is calculated for each lot using equation (14).
$\bar{X}=\frac{\sum_{i=1}^{n} X_{i}}{n}$

Where $\overline{\mathrm{X}}$ is the arithmetic mean cycle time value, $X_{i}$ is the individual lot cycle time and $n$ is the number of lots under observation. This enables us to understand the behaviour of the model.

The yield loses is usually a small percentage which does not significantly affect the number of lots circulating in the system. Large yield losses can affect the number of lots in the operation and jeopardizes the functionality of the operation. Table 2 and 3 shows the comparison results of the analytical and simulation results for both the total cycle time and mean throughput for some of the $\operatorname{Dr}_{T}$ values.

The number of lots circulating in the operation is an important factor for the validity of the model. This is because when large number of lots resides in the system, the exit time from the operation becomes longer and this creates a larger deviation from the simulation values. Based on our experiments, when the operation has more than 60 lots, the error exceeds the 5\% error limit. This is especially true for the lower $\mathrm{r}_{\mathrm{T}}$ values. Due to this and in order to establish a standard cutoff across all the $\mathrm{Dr}_{\mathrm{T}}$ values, $\mathrm{N}=60$ is considered and all the experiments were tested to this extend.

Table 4 shows the average total cycle time error for different $\operatorname{Dr}_{\mathrm{T}}$ values, which were tested for lot up to 60 , and the obtained average errors are below 5\%. Considering the combinational routing probabilities results, the lowest values attained is at 0.41 . Values below 0.41 would create errors larger than $5 \%$. Using these results, the $\mathrm{r}_{T}$ values is tested from 0.41 to 1 with cumulative yield probabilities not less than 0.7 . 
TABLE 1: COMBINATIONAL ROUTING WITH YIELD PROBABILITIES

\begin{tabular}{|c|c|c|c|c|c|c|c|c|c|c|c|}
\hline $\mathrm{P}$ & $\mathrm{r}_{1}$ & $\mathrm{r}_{2}$ & $\mathrm{r}_{3}$ & $\mathrm{rT}$ & $\mathrm{d}_{1}$ & $\mathrm{~d}_{2}$ & $\mathrm{~d}_{3}$ & $\mathrm{~d}_{4}$ & $\mathrm{~d}_{5}$ & $\mathrm{D}_{\mathrm{T}}$ & DrT \\
\hline \multirow[t]{11}{*}{3} & 0 & 0 & 1 & 1 & 0 & 0 & 0 & 0 & 0 & 1 & 1 \\
\hline & 0 & 0.50 & 0.50 & 0.83 & 0 & 0.01 & 0.02 & 0.03 & 0.10 & 0.85 & 0.54 \\
\hline & 0 & 0.40 & 0.60 & 0.87 & 0 & 0.01 & 0.02 & 0.03 & 0.10 & 0.85 & 0.56 \\
\hline & 0.60 & 0.30 & 0.10 & 0.50 & 0 & 0.01 & 0.02 & 0.03 & 0.10 & 0.85 & 0.37 \\
\hline & 0.24 & 0.21 & 0.54 & 0.77 & 0 & 0.01 & 0.02 & 0.03 & 0.10 & 0.85 & 0.50 \\
\hline & 0.75 & 0.00 & 0.25 & 0.50 & 0 & 0.01 & 0.02 & 0.03 & 0.15 & 0.80 & 0.33 \\
\hline & 0.01 & 0.88 & 0.11 & 0.70 & 0 & 0.01 & 0.02 & 0.03 & 0.15 & 0.80 & 0.43 \\
\hline & 0.40 & 0.07 & 0.53 & 0.71 & 0 & 0.01 & 0.02 & 0.03 & 0.15 & 0.80 & 0.41 \\
\hline & 0.24 & 0.71 & 0.05 & 0.60 & 0 & 0.01 & 0.02 & 0.03 & 0.20 & 0.75 & 0.35 \\
\hline & 0.00 & 0.38 & 0.62 & 0.87 & 0 & 0.01 & 0.02 & 0.03 & 0.18 & 0.77 & 0.44 \\
\hline & 0.77 & 0.23 & 0.01 & 0.41 & 0 & 0.01 & 0.02 & 0.03 & 0.25 & 0.71 & 0.26 \\
\hline
\end{tabular}

TABLE 2: ANALYTICAL AND SIMULATION RESULTS FOR TOTAL CYCLE TIME

\begin{tabular}{|c|c|c|c|c|c|c|c|c|c|c|c|c|}
\hline \multirow[b]{3}{*}{$\mathrm{N}$} & \multicolumn{12}{|c|}{ Total cycle time } \\
\hline & \multicolumn{3}{|c|}{ DrT $=0.54$} & \multicolumn{3}{|c|}{ DrT $=0.37$} & \multicolumn{3}{|c|}{ DrT $=0.43$} & \multicolumn{3}{|c|}{$\mathrm{DrT}=0.26$} \\
\hline & $\begin{array}{c}\text { MVA } \\
\text { (hrs) }\end{array}$ & $\begin{array}{l}\text { Sim } \\
\text { (hrs) }\end{array}$ & $\begin{array}{c}\text { Error } \\
(\%)\end{array}$ & $\begin{array}{c}\text { MVA } \\
\text { (hrs) }\end{array}$ & Sim (hrs) & $\begin{array}{c}\text { Error } \\
(\%)\end{array}$ & $\begin{array}{c}\text { MVA } \\
\text { (hrs) }\end{array}$ & Sim (hrs) & $\begin{array}{c}\text { Error } \\
(\%)\end{array}$ & $\begin{array}{c}\text { MVA } \\
\text { (hrs) }\end{array}$ & $\begin{array}{l}\text { Sim } \\
\text { (hrs) }\end{array}$ & $\begin{array}{c}\text { Error } \\
(\%) \\
\end{array}$ \\
\hline 5 & 4.73 & 4.64 & 2.03 & 3.33 & 3.21 & 3.74 & 3.82 & 3.67 & 4.09 & 2.43 & 2.55 & 4.71 \\
\hline 10 & 8.37 & 8.10 & 3.31 & 5.83 & 5.61 & 3.92 & 6.73 & 6.46 & 4.18 & 4.19 & 4.01 & 4.49 \\
\hline 15 & 12.32 & 11.92 & 3.36 & 8.53 & 8.25 & 3.39 & 9.87 & 9.47 & 4.22 & 6.08 & 6.39 & 4.85 \\
\hline 20 & 16.34 & 15.81 & 3.35 & 11.29 & 10.91 & 3.48 & 13.07 & 12.52 & 4.39 & 8.02 & 8.41 & 4.64 \\
\hline 30 & 24.44 & 23.62 & 3.47 & 16.84 & 16.27 & 3.50 & 19.52 & 18.72 & 4.27 & 11.92 & 11.42 & 4.38 \\
\hline 50 & 40.64 & 42.15 & 3.58 & 27.94 & 28.89 & 3.29 & 32.42 & 31.09 & 4.28 & 19.72 & 18.83 & 4.73 \\
\hline 60 & 48.74 & 49.90 & 2.32 & 33.49 & 34.94 & 4.15 & 38.87 & 37.45 & 3.79 & 23.62 & 22.63 & 4.37 \\
\hline
\end{tabular}

TABLE 3: ANALYTICAL AND SIMULATION RESULTS FOR MEAN THROUGHPUT

\begin{tabular}{|c|c|c|c|c|c|c|c|c|c|c|c|c|}
\hline \multirow[b]{3}{*}{$\mathrm{N}$} & \multicolumn{12}{|c|}{ Mean throughput } \\
\hline & \multicolumn{3}{|c|}{$\mathrm{Dr}_{\mathrm{T}}=0.54$} & \multicolumn{3}{|c|}{$\mathrm{Dr}_{\mathrm{T}}=0.37$} & \multicolumn{3}{|c|}{$\mathrm{Dr}_{\mathrm{T}}=0.43$} & \multicolumn{3}{|c|}{$\operatorname{Dr}_{T}=0.26$} \\
\hline & $\begin{array}{l}\text { MVA } \\
\text { (lots/ } \\
\text { hour) }\end{array}$ & $\begin{array}{c}\text { Sim } \\
\text { (lots/hour) }\end{array}$ & $\begin{array}{c}\text { Error } \\
(\%)\end{array}$ & $\begin{array}{l}\text { MVA } \\
\text { (lots/ } \\
\text { hour) }\end{array}$ & $\begin{array}{c}\text { Sim } \\
\text { (lots/hour) }\end{array}$ & $\begin{array}{c}\text { Error } \\
(\%)\end{array}$ & $\begin{array}{l}\text { MVA } \\
\text { (lots/ } \\
\text { hour) }\end{array}$ & $\begin{array}{c}\text { Sim } \\
\text { (lots/hour) }\end{array}$ & $\begin{array}{c}\text { Error } \\
(\%)\end{array}$ & $\begin{array}{l}\text { MVA } \\
\text { (lots/ } \\
\text { hour) }\end{array}$ & $\begin{array}{c}\text { Sim } \\
\text { (lots/ } \\
\text { hour) }\end{array}$ & $\begin{array}{c}\text { Error } \\
(\%)\end{array}$ \\
\hline 5 & 1.06 & 1.087 & 2.76 & 1.50 & 1.558 & 3.64 & 1.31 & 1.362 & 4.07 & 2.06 & 1.980 & 4.04 \\
\hline 10 & 1.19 & 1.243 & 3.94 & 1.72 & 1.783 & 3.79 & 1.49 & 1.548 & 4.00 & 2.39 & 2.307 & 3.55 \\
\hline 15 & 1.22 & 1.267 & 3.89 & 1.76 & 1.818 & 3.31 & 1.52 & 1.584 & 4.04 & 2.47 & 2.365 & 4.23 \\
\hline 20 & 1.22 & 1.268 & 3.50 & 1.77 & 1.833 & 3.39 & 1.53 & 1.597 & 4.22 & 2.49 & 2.378 & 4.79 \\
\hline 30 & 1.23 & 1.278 & 3.90 & 1.78 & 1.844 & 3.36 & 1.54 & 1.603 & 4.09 & 2.52 & 2.627 & 4.22 \\
\hline 50 & 1.23 & 1.273 & 3.38 & 1.79 & 1.844 & 2.93 & 1.54 & 1.608 & 4.12 & 2.54 & 2.629 & 3.58 \\
\hline 60 & 1.23 & 1.274 & 3.34 & 1.79 & 1.845 & 2.87 & 1.54 & 1.609 & 4.04 & 2.54 & 2.629 & 3.39 \\
\hline
\end{tabular}

Higher yield losses would create instability in the system, as the number of lots exiting the operation would be larger before completing all the stages of work. Results show that the errors obtained are less than 5\%. Larger error values will result if the routing probabilities and cumulative yield probabilities chosen are out of the specified range. Our results confirm that the algorithm could be utilized to closely model our type of operation with respect to mentioned performance measure as the error is less than $5 \%$ and within the specified combinational routing with yield probabilities limits. The acceptable $5 \%$ error limits has been acknowledged and used in the works of Narahari and Khan [6] and Park et al. $[7,8]$. Due to the limitation of the paper length, some of the detail results are only presented 
and interested readers may obtain details from the author. The algorithm is capable to compute the total cycle time required to process a defined number of lots.

TABle 4: AVERAGE TOTAL CYClE TIME ERROR

\begin{tabular}{|l|cc|}
\hline $\mathrm{P}$ & DrT & Average total cycle time error (\%) \\
\hline 3 & 1 & 2.98 \\
\cline { 2 - 3 } & 0.54 & 3.06 \\
\cline { 2 - 3 } & 0.56 & 3.04 \\
\cline { 2 - 3 } & 0.37 & 4.48 \\
\cline { 2 - 3 } & 0.50 & 3.07 \\
\cline { 2 - 3 } & 0.33 & 4.53 \\
\cline { 2 - 3 } & 0.43 & 4.17 \\
\cline { 2 - 3 } & 0.41 & 4.42 \\
\cline { 2 - 3 } & 0.35 & 4.50 \\
\cline { 2 - 3 } & 0.44 & 4.34 \\
\cline { 2 - 3 } & 0.26 & 4.59 \\
\hline
\end{tabular}

As it was expected, our experiment shows that, the mean throughput increases when the number of lots in the operation is small and tends to be constant when the number of lots becomes larger. The throughput behaviour mimics a logarithmic function. The point when the throughput starts to saturate is taken as the maximum point. Each combinational routing and yield probability will have its maximum number of lots and target cycle time as shown in Table 5 and they become the baseline for the operation. In the event where there is a need to increase the number of lots into the operation, the mean throughput will not be affected.

TABLE 5: MAXIMUM NUMBER OF LOTS AND CYCLE TIME GOAL FOR VARIOUS COMBINATIONAL ROUTING AND YIELD PROBABILITIES.

\begin{tabular}{|ccc|}
\hline $\mathrm{Dr}_{\mathrm{T}}$ & $\begin{array}{c}\text { Maximum number } \\
\text { of lots, } \mathrm{N}_{\max }\end{array}$ & $\begin{array}{c}\text { Target cycle time } \\
\mathrm{T}_{\text {goal }} \text { (hours) }\end{array}$ \\
\hline 0.26 & 29 & 11.53 \\
\hline 0.33 & 23 & 11.59 \\
\hline 0.35 & 23 & 12.27 \\
\hline 0.37 & 18 & 10.19 \\
\hline 0.41 & 18 & 11.25 \\
\hline 0.43 & 17 & 11.15 \\
\hline 0.50 & 15 & 11.43 \\
\hline 0.54 & 15 & 12.32 \\
\hline 0.56 & 15 & 12.76 \\
\hline 1.00 & 11 & 16.68 \\
\hline
\end{tabular}

However, the total cycle time will increase proportionally and will exceed the targeted cycle time defined by the Power Soak operation for any of the routings.

\section{CONCLUSION}

In this paper, we proposed an analytical model based on the mean value analysis technique to determine the total cycle time and mean throughput for a Power Soak operation in a semiconductor back-end industry. The research was conducted in a Power Soak operation in a semiconductor back-end manufacturing industry. Thus, the following conclusions are outlined:

1. The Power Soak operation basically has two re-entrant lines $(\mathrm{P}=3)$ with routing probabilities. This is the basic structure of the operation and different routing probabilities were tested. Comparison results show that the cumulative routing probabilities should not go below 0.41 in order to have an error within 5\%. The 5\% error is considered an acceptable limit for a good estimation. The number of lots in the operation also plays an important role in determining the accuracy of the model.

2. Based on the computational experiment, the number of lots circulating in the Power Soak operation should be limited to 60. Having more than 60 lots residing in the operation would create an error exceeding 5\%. Thus, the model has its limitation depending on the accuracy level that is acceptable and is defined for the algorithm to work accurately. However, this limitation does not reflect the capacity of the system.

3. Yield losses occur as the lots go through operation. However, the yield losses have to be at a manageable level whereby very large yield losses would create a drastic imbalance in the number of lots in the 
operation. Results show that the cumulative yield probabilities should be more than 0.7 in order to have a $5 \%$ tolerance in both the total cycle time and mean throughput.

4. Determining the capacity of the operation is an important factor as it outlines the limitation of the operation in terms of the number of lots and cycle time. The mean throughput information is utilised to determine the capacity. The $\mathrm{N}_{\max }$ relates to the maximum number of lots the operation is able to cater for a specified combinational routing probabilities. $\mathrm{T}_{\text {goal }}$ corresponds the total cycle that the $\mathrm{N}_{\max }$ is able to achieve. This provides the manager with capacity information and becomes the operation baseline which can be used to plan and to receive lots within the limits. Receiving lots beyond $\mathrm{N}_{\max }$ will increase the cycle time but not the flow rate of the lots through the system. Thus, congestion will occur at the buffers.

The contribution of this work is the extension of the MVA technique to include combinational routing and yield probabilities and lot clustering method to represent the probabilistic nature of the re-entrant line. The advantage of this method is that the decision maker is able to compute the total cycle time in terms of the number of lots to be loaded into the operation within some limits. This work is further enhanced by developing a method to determine the maximum number of lots and the target cycle time for the operation to handle. These values become a baseline for a particular combinational routing probability with some yield consideration. Future work could consider assignment of workforce in the event of lot exceeding the baseline values.

\section{NOMENCLATURE}

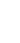

j

l

$\mathrm{k}$

$\mu_{\mathrm{i} l} \quad$ mean processing rate of a lot at buffer $\mathrm{b}_{\mathrm{i} l}$

$\lambda(\mathrm{k}) \quad$ throughput rate when the operation has k lots

$\mathrm{r}_{l} \quad$ routing probability of $l$ th cycle

$\mathrm{r}_{\mathrm{T}} \quad$ combinational routing probability

$\mathrm{b}_{\mathrm{i} l} \quad$ buffers at stage i for $l$ th cycle

$d_{i} \quad$ defect probabilities or yield losses at stage $\mathrm{i}$

$\mathrm{D}_{\mathrm{T}} \quad$ cumulative yield probability

$\mathrm{L}_{\mathrm{i}}(\mathrm{k}) \quad$ mean number of lots waiting at $\mathrm{b}_{\mathrm{i} l}$ with $\mathrm{k}$ number lots in the system

$\mathrm{W}_{\mathrm{i} /}(\mathrm{k}) \quad$ mean waiting time of a lot in $\mathrm{b}_{\mathrm{i} / \mathrm{when}}$ the operation has $\mathrm{k}$ number of lots

W (k) total waiting time for stage 2, 3, 4 and 5 with $\mathrm{k}$ number of lots

$\mathrm{W}_{\mathrm{T}}(\mathrm{k}) \quad$ total cycle time of $\mathrm{k}$ number of lots going through all buffers

$\mathrm{DW}_{\mathrm{T}}(\mathrm{k})$ total cycle time when applying combinational routing with yield probabilities

\section{REFERENCES}

[1] Gross D., Harris, C.M., Networks, Series and Cyclic Queue, Fundamentals of Queueing Theory, New York: John Wiley \& Sons, Inc, 1998, p.p 165-198.

[2] Kumar S. and Omar M.K., "Stochastic re-entrant line modeling for an environmental stress testing in a semiconductor assembly industry", Applied Mathematics and Computation, Vol. 173, 2006, 603-615.

[3] Kumar S. and Omar M.K., "Performance measure in a probabilistic reflow screening line using mean 
value analysis", The AIUB Journal of Science and Engineering (ASJE), Vol. 4 (1), 2005, p.p 53-58.

[4] Kumar, S., "Modeling of a probabilistic reentrant line bounded by limited operation utilization time", Journal of Industrial and System Engineering, Vol. 2 (1), 2008, p.p 28-40.

[5] Little J.D.C., "A proof for the queueing formula: $\mathrm{L}=\lambda$ W". Operations Research, Vol. 9, 1961, p.p 383-387.

[6] Narahari Y. and Khan L,M., "Modeling re-entrant manufacturing systems with inspections", Journal of Manufacturing Systems, Vol. 15, 1996, p.p 367-378.

[7] Park Y, Kim S, Jun C.H., "Mean value analysis of re-entrant line with batch machines and multiclass jobs", Computers and Operations Research, Vol. 29, 2002, p.p 1009-1024.

[8] Park Y, Kim S, Jun C.H., "Performance evaluation of re-entrant manufacturing operation with production loss using mean value analysis", Computers and Operations Research, Vol. 33, 2006, p.p 1308-1325.

[9] Reiser M, Lavenberg S.S., "Mean-value analysis of closed multichain queueing networks", Journal of the Association for Computing Machinery, Vol. 27 (2), 1980, p.p 313-322.

[10] Taylor Enterprise Dynamics, "Taylor ED 2000: User manual-tutorial", F\&H Simulations B.V, 2000, Utrecht, the Netherlands.

[11] Kumar S., Omar, M.K , "Performance analysis in a re-entrant operation with combinational routing and yield probabilities", Applied Mathematical Modelling, Vol. 33 (3), 2009, p.p 1601-1612.

[12] Kumar S., Arunagiri A., "An artificial neural network approach - performance measure of a reentrant line in a reflow screening operation", Journal of Engineering Science and Technology, Vol. 5 (4), 2010, p.p 447-456. 


\title{
تحليل القيمة المتوسطة وتثكيله من تحديد المسار وإحتمالات الإتتاجية لعملية تصنيع مكونات القدرة الكهربية
}

\author{
سوريش كومار
}

قسم تقنية هندسة الإكترونيات والآلات الدقيقة ، كلية ينبع الصناعية، المملكة العربية السعودية

الملخص:

شبكة الطلبيات التي تنشأ من عمليات ذات مراحل متعددة مع إحتمالية إعادة الدخول هي معروفة في بيئة التصنيع. تعرف مسار إحتمالية إعادة الدخول على أساس الكم الداخل في أي عملية ومتطلبات إعادة التدوير المختلفة. يقدم هذا البحث نموذج حسابي مبني على أساس تقنية تحليلات القيمة المتوسطة، آخذين في الإعتبار إحتمالية إعادة الدخول وإحتمالية الإنتاجية لعملية إنتاج موزع القدرة. يهذف هذا البحث إلى تطوير طريقة حل لتحديد الزمن الكلي لدورة الإنتاج ومتوسط الخرج لتصنيع موزع القدرة في صناعة تعتمد على أثباه الموصلات. هذا بالإضافة إلى تقديم طريقة تعتمد على متوسط الخلالية المتشبع لتحديد أقصى عدد من البضائع والوقت المستهاف لإتمام العطلية. بإستخدام الطرق الحسابية والمحاكاة نم الحصول على نتائج مقارنة تحت مختلف إحتمالات إعادة الاخول والإنتاج. وقد أظهرت النتائج تقارب الطريقة الحسابية مع المحاكاة. الطريقة المقترحة في هذا البحث يمكن أن بستفبد منها مدير الإنتاج في تحديد الزمن الكلي لوحدة الإنتاج و أقصى عدد من وحدات الإنتاج وبالتالي يسنطيع تحديد كفاءة التشغيل. 